\title{
A Survey of Weight-Based Clustering Algorithms in MANET
}

\author{
${ }^{1}$ Prerna Malhotra, ${ }^{2}$ Ajay Dureja \\ ${ }^{1}$ Student, PDM College of Engineering for Women, B' Garh \\ ${ }^{2}$ Assistant Professor, PDM College of Engineering for Women, B' 'Garh
}

\begin{abstract}
As MANETs haven't any mounted infrastructure, all messages have to be routed through the nodes within the network. several clustering and routing algorithms are developed for MANETs. Moreover, most of the prevailing routing algorithms don't utilize the potency that may be obtained by clustering a network. clustering method involves in grouping network nodes and facilitates in reducing the overhead messages that help in establishing routes. Moreover, there's a trade-off between providing security and preserving the ability of a node. In current approaches, clustering and routing algorithms are designed specifically for either providing security or protective power. It's terribly tough to boost each security and minimize power consumption, as usually one is achieved at the expense of the opposite. In this paper we survey about different weight based clustering algorithms designed so far.
\end{abstract}

Keywords- Clustering, MANET, Mobility, Security

\section{Introduction}

Clustering technique isn't a routing protocol, it's a technique that aggregates nodes into groups to form network management easier. Cluster organization of an ad hoc network can't be achieved offline in mounted infrastructure. The implementation of clustering schemes facilitate the performance of protocols for the Media Access Control(MAC) by improving spatial reuse, throughput, measurability and power consumption.

Clustering provides multiple advantages in MANETs. Firstly, a cluster structure ensures measurability and load leveling in MANETs. It additionally will increase the system capability by facilitating the spatial reuse of resources. In multi cluster structure, 2 non overlapping clusters might set up same frequency if they're not adjacent. Additionally it elects a mobile host with special options known as cluster head for increased coordination of transmission activities[1]. This mitigates the transmission collision of mobile nodes and therefore helps in saving energy and resources. Secondly, it restricts the generation and spreading of routing data by forming a virtual backbone for inter-cluster routing comprising of cluster heads and cluster gateways. Lastly, clustering provides a stable and smaller vision of unintended network as once a mobile node changes its attaching cluster the whole network needn't remember of the native changes in a set of nodes solely the mobile nodes within the corresponding cluster replicate the changes. thus every node stores and processes a fraction of the whole network routing data, so saving plenty of resources.

The objective of clustering is to take care of a connected cluster. Nodes play completely different roles in clustering techniques and there are 3 kinds of nodes[2]. they're outlined as follows:-

1. standard nodes

2. Cluster head

3. Cluster gateways Nodes

Clusterhead nodes: for any economical cluster (subsets of nodes in an exceedingly network satisfying a selected property) operation there should be a support or backbone to sustain all essential control functions like channel access, routing, calculation of the routes for longer-distance messages, bandwidth allocation, forwarding inter-cluster packets, power management and virtual-circuit support. This support or backbone takes the shape of connected clusterheads, in managerial role joined either directly or via gateway nodes and that they can have the subordinate nodes of that cluster joined to them. Another function of clusterheads is internal node communication, to forward intercluster messages. To send a packet a standard node should initial direct it to its 'superior' its directly connected clusterhead. ought to the receiver share a similar cluster location, clusterhead can direct the packet to that. However, ought to the receiver be in an exceedingly completely different cluster location, clusterhead can route it to a different clusterhead (directly) connected to the receiver and therefore the new clusterhead then directs it to the ultimate destination

Cluster gateway Nodes: could be a node that works because the common or distributed access purpose for 2 clusterheads. once a node remains among the transmission vary of 2 clusterheads because the node a pair of in Figure 1(b) it is known as because the standard gateway for 2 corresponding clusters. And a node having one clusterhead as a right away neighbour additionally to that it will reach a second clusterhead in two hops as node 
five or six is a distributed gateway that's joined to a different distributed gateway of alternative cluster. each of the distributed gateways give the trail for the inter-cluster communication.

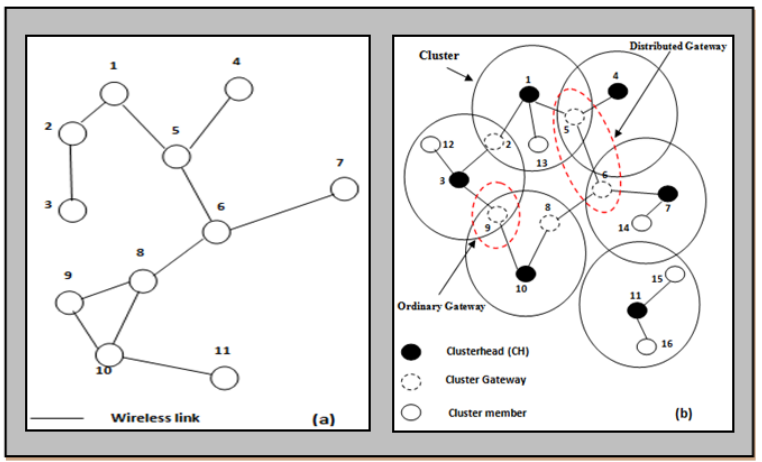

Fig 1 : Nodes in flat and cluster structure. (a) Flat structure. (b) Cluster structure

Ordinary nodes (cluster member): as the name suggests, standard nodes don't perform any other function on the far side a traditional node role. they're members of associate exclusive cluster freelance of neighbours residing in an exceedingly completely different cluster.

\section{Categories Of Clustering}

The concept of dividing a geographical region to be covered into small regions is defined as clustering. Each cluster will be uniquely identified using its cluster head. A cluster head is a node present in the geographical region of the cluster and takes care of the routing and allocation of resources for the cluster members. Nodes that have registered with the cluster head become members of the cluster. Clusters may change dynamically, reflecting the mobility of the underlying network. Some of the clustering algorithms are explained below. Most algorithms assume that all the nodes present in the network are same, that is have the same power capacity, transmission range etc. [11]

\subsection{Simple Clustering}

Some of the simple clustering methods for MANETs are given in this section. These are considered to be the basic clustering methods.

\subsubsection{Lowest ID Clustering}

Each node present in the network is given a unique ID. All the nodes communicate with their neighbors using beacons and piggybacking their ID. A node, which hears from nodes having ID value higher than itself, is a cluster head. A node can be part of multiple clusters. These nodes are called gateway nodes [3].

\subsubsection{Connectivity Clustering}

In this method all nodes broadcast the list of nodes they are able to hear from. A node that is connected to most of the highly connected uncovered neighbor nodes is elected as the cluster head. A node is said to be uncovered if it does not belong to any cluster. If more than one node has the same degree of connectivity then the decision is made on the basis of Lowest ID. Both these methods belong to single hop clustering algorithms, where any two nodes are at most two hops away and cluster heads are not directly linked [3].

\subsubsection{Cell Clustering}

This technique is used in Mobile IP, here a region is divided into cells and a group of cells are clustered. When we have lot of hand off between two cells then they are brought under one cluster.

\subsubsection{Weighted Clustering}

In this method, each node will calculate its weight based on some of its characteristics. The node with the highest weight is elected as the cluster head of that cluster [4]. Expression for weight is given as:

$$
\text { Weight }=a * \text { speed }+b * \text { degree }+c * \text { power }+d * \text { energy-left. }
$$

Where $a, b, c, d$ are positive or negative depending on circumstances.

\subsection{Enhanced Clustering}

This section describes some of the latest and more complex clustering techniques used in MANETs. 


\subsubsection{K-Cluster approach}

In this approach, a cluster is considered to be a subset of nodes, which are mutually reachable by a path of length at most $\mathrm{K}$, for some fixed $\mathrm{K}$. This is a graph based approach, where the network is considered to be a whole single connected graph. There is a path from each node to every other node through the edges of the cluster in the graph. Each node maintains three data structure tables containing the information of neighbor nodes, all the clusters and designated boundary nodes present in the network. Gateway nodes are called as the boundary nodes and one among these is given the designated boundary node status.

\subsubsection{Hierarchical Clustering}

In this graph scheme, all clusters are considered to be connected and have minimum and maximum size limitations. Some of the other constraints placed are two clusters should have low overlap and clusters should be stable across node mobility[7]. The clustering algorithm consists of two parts:

- Tree Discovery: a node in the sub-graph will initiate the spanning tree process, which is implemented using the breadth first search in the post order. Each node chooses its parents in the tree based on the shortest distance to the root.

- Cluster Formation: When a node detects its sub tree size has crossed the maximum size, it will initiate the cluster formation of its sub tree. Also when the node detects that the clustering is of poor quality then reclustering is scheduled.

\subsubsection{Dominating Sets Clustering}

In this graph scheme the clustering is done using the dominating nodes present in the graph. The dominating set for a graph $\mathrm{G}=(\mathrm{V}, \mathrm{E})$ is defined as a subset $\mathrm{S} \leq \mathrm{V}$, such that every vertex $\mathrm{U} \varepsilon \mathrm{V}$ is either in $\mathrm{S}$ or adjacent to a vertex of $\mathrm{S}$. Three colors white, gray, black are used to classify the nodes present. Initially all the nodes are colored as white and when the node is changed to black all its neighbors are changed to gray. The black nodes form the dominating set and each vertex present in the dominating set is the cluster[8][9].

\subsubsection{Max-Min D Clustering}

The approach has the following data structures and functions defined[10] :

- WINNER: after the cluster head is selected, the winning node id of a particular round is used to determine the shortest path back to the cluster head.

- SENDER: is the node that sent the winning node id, as in WINNER.

- Floodmax function: each node locally broadcasts its WINNER value to all its one hop neighbors for a given round. The largest of the WINNER values is the selected as the new WINNER value for all the nodes. This process is continued for $\mathrm{d}$ rounds.

- Floodmin function: this is similar to Floodmax and also lasts for d rounds. Except a node selects the smallest value as its WINNER instead of the largest value.

- Overtake function: during flooding the WINNER values are propagated to neighbor nodes. Overtaking is the process of selecting a new value different from the node's own id, based on the outcome of information exchange.

- Node Pairs: a node pair is any node id that occurs at least once as a WINNER in both the first Floodmax and second Floodmin d rounds of flooding, for an individual node.

In the first stage the largest node id in each node's d-neighborhood is propagated using the $\mathrm{d}$ rounds of Floodmax. Nodes record their winning node for each round and at the end of Floodmax the surviving nodes are elected as cluster heads in the network. In the second stage $\mathrm{d}$ round of Floodmin is used to propagate the smaller ids that have not been overtaken. At the conclusion of the Floodmin, each node evaluates the round's WINNER to best determine their cluster head. The following rules are given for the cluster head selection criteria.

- Rule 1: if a node has received its own id in second round of flooding then it can declare itself as the cluster head and skip the rest of the process or continue.

- Rule 2: Once a node has identified all the node pairs, it selects the minimum node pair to be the cluster head. If a node pair does not exist for a node then proceed to rule 3 .

- Rule 3: Elect the maximum node id in the first $\mathrm{d}$ rounds of flooding as the cluster head for this node.

After determining the cluster head, the node informs the cluster head about its membership. If there are neighboring nodes with cluster head selections that are different then these nodes are called as gateway nodes.

They are many other clustering algorithms that are based on the above approaches, and try to improve the efficiency of clustering. 


\section{Cost Of Clustering}

Constructing and maintaining a cluster structure requires additional cost compared to flat structure MANETs. The analysis of cost of clustering scheme is carried out quantitatively or qualitatively to outline the benefits and drawbacks of the clustering technique[2].

The cost associated with clustering is explained as below:-

1. In a dynamically changing cluster structure due to frequent change in network topology the information related to clusters vary drastically. The consequent transfer of message packets consumes substantial bandwidth and depletes the energy possessed by mobile nodes. This further disables the upper layer applications which cannot be implemented with handful of resources.

2. Re-clustering may take place in some clustering schemes due to abrupt local instance such as movement of mobile node to another cluster or death of a mobile node or even shut down of clusterheads, thus leading to reelection of clusterheads. This is known as ripple effect of re-clustering which stimulates this effect of reclustering over the entire network.

3. Clustering scheme is divided into two stages: cluster formation and maintenance. The formation stage assumes that the mobile nodes are static. With a frozen period of motion, each mobile node can obtain accurate information from neighbouring nodes, which may not be applicable in real time scenario.

\section{Related Works}

A lot of research has been done on weight based clustering algorithms in MANET. Below shows few algorithms based on weighted mechanism to make clusters

\subsection{An Efficient Weight-based clustering algorithm for MANET}

Mohammad Reza Monsef et al, proposed an efficient weight-based clustering algorithm (EWBCA) for mobile ad hocnetworks (MANETs). It aims to improve the usage of scarce resources such as bandwidth and energy, preserve current clusterstructure as much as possible, minimize routing overhead, and increase end-to-end throughput. In our algorithm, each node hasa quality that indicates its suitability as a cluster head. This quality is calculated according to following four parameters: Numberof Neighbors, Residual Power of Battery, Stability and Variance of distance with all neighbors. The result shows the simulation of the algorithm.[12]

\begin{tabular}{|c|c|c|}
\hline $\begin{array}{c}\text { No. of } \\
\text { Nodes }\end{array}$ & $\begin{array}{c}\text { End-to End } \\
\text { Throughput }\end{array}$ & $\begin{array}{c}\text { Energy } \\
\text { Consumption }\end{array}$ \\
\hline 10 to 60 & $\begin{array}{c}\text { Increases by } \\
10.2 \%\end{array}$ & Very small \\
& \multicolumn{2}{|c|}{} \\
\hline
\end{tabular}

\subsection{Stable and Flexible Weight based Clustering Algorithm in Mobile Ad hoc Networks}

R. Pandi Selvam et al., have concentrated to design a new weight based clustering algorithm to improve the performance in this wireless technology.

Simulation experiments are conducted to evaluate the performance of our algorithm in the transmission range, number of nodes and maximum displacement. Results are shown that our algorithm performs better than existing g algorithms. [13]

\begin{tabular}{|c|c|c|c|}
\hline $\begin{array}{c}\text { No. of } \\
\text { Nodes }\end{array}$ & $\begin{array}{l}\text { Simulation } \\
\text { time }\end{array}$ & $\begin{array}{l}\text { Transmission } \\
\text { range }\end{array}$ & $\begin{array}{c}\text { Number of } \\
\text { clusters } \\
\text { formed }\end{array}$ \\
\hline 50 to 300 & $200 \mathrm{~s}$ & Minimum & Minimum \\
\hline
\end{tabular}

\subsection{WACA: A Hierarchical Weighted Clustering Algorithm optimized for Mobile Hybrid Networks}

Matthias R. Brust et al., investigations focus on the problem of minimizing clusterhead re-elections by considering stability criteria. These criteria are based on topological characteristics as well as on device parameters. This paper presents a weighted clustering algorithm optimized to avoid needless clusterhead reelections for stable clusters in mobile ad-hoc networks. The proposed localized algorithm deals with mobility, but does not require geographical, speed or distances information. [14]

\begin{tabular}{|c|c|c|}
\hline $\begin{array}{c}\text { No. of } \\
\text { Nodes }\end{array}$ & Transmission range & $\begin{array}{c}\text { Number of clusters } \\
\text { head election }\end{array}$ \\
\hline 20 to 60 & Minimum & Decreased \\
\hline
\end{tabular}




\subsection{A Robust Clustering Algorithm for Mobile Ad Hoc Networks}

Zhaowen Xing et al, presents a robust weighted clustering algorithm, called PMW (Power, Mobility and Workload), to form and maintain more stable clusters. In PMW, the weight of each node is calculated by its power, mobility and workload, which can be easily collected and computed locally and cover the major factors that cause re-clustering. Clustering overhead of PMW is analyzed. The simulation results confirm that PMW prolongs lifetime of MANETs and has a lower cluster head change rate and re-affiliation rate than other existing algorithms.[15]

\begin{tabular}{|c|c|c|c|c|}
\hline $\begin{array}{l}\text { No. of } \\
\text { Nodes }\end{array}$ & $\begin{array}{l}\text { Simulation } \\
\text { time }\end{array}$ & $\begin{array}{l}\text { Transmiss } \\
\text { ion range }\end{array}$ & $\begin{array}{c}\text { Network } \\
\text { lifetime }\end{array}$ & $\begin{array}{c}\text { Number } \\
\text { of clusters } \\
\text { head } \\
\text { election }\end{array}$ \\
\hline 50 & $200 \mathrm{~s}$ & $\begin{array}{c}10 \mathrm{~m}- \\
250 \mathrm{~m}\end{array}$ & $9 \%$ to $42 \%$ & lesser \\
\hline
\end{tabular}

\subsection{A Load-Balancing and Weighted Clustering Algorithm in Mobile Ad-Hoc Network}

Abdel Rahman H. Hussein et al, proposed that the enhancement on weighted clustering algorithm (EWCA), leads to a high degree of stability in the network and improves the load balancing. In this simulation study, a comparison was conducted to measure the performance of our algorithm with original WCA in terms of numbers of clusters formed with satisfy load balancing, topology stability, and number of clusterhead change.[16]

\begin{tabular}{|c|c|l|l|c|c|}
\hline $\begin{array}{l}\text { No. of } \\
\text { Nodes }\end{array}$ & $\begin{array}{l}\text { Simulatio } \\
\mathrm{n} \text { time }\end{array}$ & $\begin{array}{l}\text { Transmis } \\
\text { sion } \\
\text { range }\end{array}$ & $\begin{array}{l}\text { Clusters } \\
\text { formed }\end{array}$ & Stability & $\begin{array}{c}\text { Load } \\
\text { balancing }\end{array}$ \\
\hline $30-300$ & $200 \mathrm{~s}$ & $0 \mathrm{~m}-200 \mathrm{~m}$ & lesser & $\begin{array}{c}20 \%-70 \% \\
\text { more }\end{array}$ & $\begin{array}{c}25 \text { times } \\
\text { more } \\
\text { balanced }\end{array}$ \\
\hline
\end{tabular}

\subsection{WCA: A Weighted Clustering Algorithm for Mobile Ad Hoc Networks}

Mainak chatterjee et al, proposed weight-based distributed clustering algorithm takes into consideration the ideal degree, transmission power, mobility, and battery power of mobile nodes. The time required to identify the clusterheads depends on the diameter of the underlying graph. We try to keep the number of nodes in a cluster around a pre-defined threshold to facilitate the optimal operation of the medium access control (MAC) protocol. The non-periodic procedure for clusterhead election is invoked on-demand, and is aimed to reduce the computation and communication costs. The clusterheads, operating in "dual" power mode, connects the clusters which help in routing messages from a node to any other node.[17]

\begin{tabular}{|c|c|c|c|}
\hline $\begin{array}{l}\text { No. of } \\
\text { Nodes }\end{array}$ & $\begin{array}{l}\text { Simulation } \\
\text { time }\end{array}$ & $\begin{array}{l}\text { Transmissio } \\
\mathrm{n} \text { range }\end{array}$ & reaffilations \\
\hline $20-60$ & $200 \mathrm{~s}$ & $0 \mathrm{~m}-70 \mathrm{~m}$ & $50 \%$ more \\
\hline
\end{tabular}

\subsection{An Innovative Clustering Algorithm for MANETs Based on Cluster Stability}

Mohammad Shayesteh and Nima Karimi, presented a new clustering algorithm in Mobile Ad Hoc Network based on nodes weight.

For calculating node weight we present four new parameter,relative speed, stability, number of nodes moving towards a node and battery remaining. The goal of this algorithm is todecrease the number of cluster forming, maintain stable clustering structure and maximize lifespan of mobile nodes in the system.[18]

\begin{tabular}{|c|c|c|c|}
\hline $\begin{array}{l}\text { No. of } \\
\text { Nodes }\end{array}$ & $\begin{array}{l}\text { Simulation } \\
\text { time }\end{array}$ & $\begin{array}{l}\text { Lifetime of } \\
\text { network }\end{array}$ & Stability \\
\hline $20-100$ & $1200 \mathrm{~s}$ & Increase & Increases \\
\hline
\end{tabular}




\section{Summary}

Clustering will offer an outsized scale Manet with hierarchal network structures to beat the difficulties of crucial quantifiability and message flooding that impair the function of flat structure of MANETs. It brings attention to important components relating to routing operations, network management, mobility management, quality of service support etc.

So far, it's been demonstrated that a cluster-based manet has various vital problems to look at as well as the steadiness of cluster structure, the management overhead of cluster construction and maintenance, the energy consumption of mobile nodes with totally different cluster-related status, the traffic load distribution in clusters, and therefore the fairness of serving as clusterheads for a mobile node.

In addition different weight based schemes have their own role in the clustering structures. And the results shown by the above algorithms also achieve goals. The summary of all the algorithms is being shown in table below.

Table 1: Comparison of different weight-based algorithms

\begin{tabular}{|c|c|c|c|c|c|c|}
\hline $\begin{array}{l}\text { Name of the } \\
\text { paper }\end{array}$ & Resource & $\begin{array}{l}\text { Selection of } \\
\text { Clusterhead }\end{array}$ & $\begin{array}{l}\text { Network } \\
\text { lifetime }\end{array}$ & Stability & $\begin{array}{l}\text { Transmission } \\
\text { range }\end{array}$ & Result \\
\hline $\begin{array}{l}\text { An } \\
\text { Efficient } \\
\text { Weight- } \\
\text { based } \\
\text { clustering } \\
\text { algorithm } \\
\text { for } \\
\text { MANET }\end{array}$ & $\begin{array}{l}\text { Journal of } \\
\text { computing }\end{array}$ & $\begin{array}{l}\text { Node wit } \\
\text { highest weight }\end{array}$ & & & Minimum & $\begin{array}{l}\text { Uses less } \\
\text { energy and } \\
\text { throughput has } \\
\text { increased }\end{array}$ \\
\hline $\begin{array}{l}\text { Stable and } \\
\text { Flexible } \\
\text { Weight based } \\
\text { Clustering } \\
\text { Algorithm in } \\
\text { Mobile Ad } \\
\text { hoc Networks }\end{array}$ & $\begin{array}{l}\text { International } \\
\text { Journal of } \\
\text { Computer } \\
\text { Science and } \\
\text { Information } \\
\text { Technologies }\end{array}$ & $\begin{array}{l}\text { Node with } \\
\text { largest weight }\end{array}$ & & More stable & Minimum & $\begin{array}{l}\text { Performance } \\
\text { is much better }\end{array}$ \\
\hline $\begin{array}{l}\text { WACA: A } \\
\text { Hierarchical } \\
\text { Weighted } \\
\text { Clustering } \\
\text { Algorithm } \\
\text { optimized for } \\
\text { Mobile } \\
\text { Hybrid } \\
\text { Networks } \\
\end{array}$ & & $\begin{array}{l}\text { Node wit } \\
\text { highest weight }\end{array}$ & & Increased & Minimum & $\begin{array}{l}\text { Optimized } \\
\text { clusterheads } \mathrm{n} \\
\text { formation of } \\
\text { clusters }\end{array}$ \\
\hline $\begin{array}{l}\text { A Robust } \\
\text { Clustering } \\
\text { Algorithm for } \\
\text { Mobile Ad } \\
\text { Hoc Networks }\end{array}$ & $\begin{array}{l}\text { Handbook of } \\
\text { Research on } \\
\text { Next } \\
\text { Generation } \\
\text { Networks and } \\
\text { Ubiquitous } \\
\text { Computing }\end{array}$ & $\begin{array}{l}\text { Based on new } \\
\text { formula of } \\
\text { weight } \\
\text { (PMW) }\end{array}$ & $\begin{array}{l}9 \% \text { to } 42 \% \\
\text { increased }\end{array}$ & More stable & $10 \mathrm{~m}-250 \mathrm{~m}$ & $\begin{array}{l}\text { Increases } \\
\text { lifetime of } \\
\text { network and } \\
\text { has lower } \\
\text { clusterhead } \\
\text { election rate }\end{array}$ \\
\hline $\begin{array}{l}\text { A Load- } \\
\text { Balancing and } \\
\text { Weighted } \\
\text { Clustering } \\
\text { Algorithm in } \\
\text { Mobile Ad- } \\
\text { Hoc Network }\end{array}$ & & $\begin{array}{l}\text { Node with } \\
\text { smallest } \\
\text { weight }\end{array}$ & $\begin{array}{l}\text { Improves } \\
\text { lifetime }\end{array}$ & $\begin{array}{l}\text { Higher degree } \\
\text { of stability }\end{array}$ & $0 \mathrm{~m}-200 \mathrm{~m}$ & $\begin{array}{l}\text { Less } \\
\text { clusterheads } \\
\text { formed more } \\
\text { stable and } \\
\text { balanced }\end{array}$ \\
\hline
\end{tabular}




\begin{tabular}{|c|c|c|c|c|c|c|}
\hline $\begin{array}{l}\text { WCA: A } \\
\text { Weighted } \\
\text { Clustering } \\
\text { Algorithm for } \\
\text { Mobile Ad } \\
\text { Hoc Networks }\end{array}$ & $\begin{array}{l}\text { Cluster } \\
\text { Computing } 5\end{array}$ & $\begin{array}{l}\text { Node with } \\
\text { smallest } \\
\text { weight }\end{array}$ & & Little Stable & $0 m-70 m$ & $\begin{array}{l}\text { Number of } \\
\text { reaffiliations } \\
\text { had increased }\end{array}$ \\
\hline $\begin{array}{l}\text { An Innovative } \\
\text { Clustering } \\
\text { Algorithm for } \\
\text { MANETs } \\
\text { Based on } \\
\text { Cluster } \\
\text { Stability }\end{array}$ & $\begin{array}{l}\text { International } \\
\text { Journal of } \\
\text { Modeling and } \\
\text { Optimization }\end{array}$ & $\begin{array}{l}\text { Node with } \\
\text { highest weight }\end{array}$ & Increased & Most stable & Maximum & $\begin{array}{l}\text { Decrease the } \\
\text { number of } \\
\text { cluster } \\
\text { forming, } \\
\text { maintain } \\
\text { stable } \\
\text { clustering } \\
\text { structure and } \\
\text { maximize } \\
\text { lifespan of } \\
\text { mobile nodes }\end{array}$ \\
\hline
\end{tabular}

\section{References}

[1] Agarwal, R., \& Mahesh, M. (2009). Survey of Clustering Algorithms for MANET. International Journal on Computer Science and Engineering, Vol.1 (2), 2009, (pp. 98-104).

[2] Ismail Ghazi Shayeb, AbdelRahman Hamza Hussein and Ayman Bassam Nasoura(2011). A Survey of Clustering Schemes for Mobile Ad-Hoc Network (MANET), American Journal of Scientific Research, 20, (pp. 135-151).

[3] Mario Gerla and Jack Tzu-Chieh Tsai, "Multicluster, mobile,multimedia radio network", Wireless Networks, Vol. 1, No. 3, pp. 255265, March 1995.

[4] Mainak Chatterjee, Sajal K. Das, and Damla Turgut, "WCA: A Weighted Clustering Algorithm for Mobile Ad Hoc Networks", Cluster Computing, Vol. 5, No. 2, pp. 193-204, April 2002.

[5] Geng Chen, Fabian Garcia Nocetti, Julio Solano Gonzalez, and Ivan Stojmenovic, "Connectivity Based k-hop Clustering in Wireless Networks", Proceedings of the 35th Hawaii International onference on System Sciences, pp. 2450-2459, Big Island, Hawaii, January 2002.

[6] Dongkyun Kim, Seokjae Ha, and Yanghee Choi, "K-hop Cluster-basedDynamic Source Routing in Wireless Ad-Hoc Packet Radio Network", Proceedings of the 48th IEEE conference on Vehicular Technology, pp. 224-228,

[7] Suman Banerjee and Samir Khuller, "A Clustering Scheme for Hierarchical Control in Multi-hop Wireless Networks", Proceedings of the Twentieth Annual Joint Conference of the IEEE Computer and Communications Societies Anchorage, Alaska, April 2001.

[8] Khaled M. Alzoubi, Peng-Jun Wan, and Ophir Frieder, "New Distributed Algorithm for Connected Dominating Set in Wireless Ad Hoc Networks", Proceedings of the 35th Hawaii International Conference on SystemSciences, pp. 3849- 3855, Big Island Hawaii, January 2002.

[9] Yuanzhu Peter Chen and Arthur L. Liestman, “Approximating Minimum Size Weakly-Connected Dominating Sets for Clustering Mobile AdHoc Networks", Proceedings of the 3rd ACM international symposium on Mobile ad hoc networking \& computing, pp. 165-172, Lausanne, Switzerland, June 2002.

[10] Alan D. Amis, Ravi Prakash, Thai H.P. Vuong, and Dung T. Huynh,"Max-Min D-Cluster Formation in Wireless Ad Hoc Networks", Proceedings of the Nineteenth Annual Joint Conference of the IEEE Computer andCommunication Societies, pp. 32-41, Tel-Aviv, Israel, March 2000.

[11] sudheer krishna chimbli venkata "SECTOR BASED CLUSTERING \& ROUTING”, December 2004

[12] Mohammad Reza Monsef, Sam Jabbehdari and Farshad Safaei, "An Efficient Weight-based clustering algorithm for MANET", JOURNAL OF COMPUTING, VOLUME 3, ISSUE 1, JANUARY 2011, ISSN 2151-9617

[13] R. Pandi Selvam and V.Palanisamy, "Stable and Flexible Weight based Clustering Algorithm in Mobile Ad hoc Networks", (IJCSIT) International Journal of Computer Science and Information Technologies, Vol. 2 (2), 2011,824-828

[14] Matthias R. Brust, Adrian Andronache and Steffen Rothkugel, "WACA: A Hierarchical Weighted Clustering Algorithm optimized for Mobile Hybrid Networks".

[15] Zhaowen Xing, Le Gruenwald and K.K. Phang, "A Robust Clustering Algorithm for Mobile Ad Hoc Networks", Handbook of Research on Next Generation Networks and Ubiquitous Computing, December 2008.

[16] Abdel Rahman H. Hussein, Sufian Yousef, and Omar Arabiyat, "A Load-Balancing and Weighted Clustering Algorithm in Mobile Ad-Hoc Network".

[17] MAINAK CHATTERJEE, SAJAL K. DAS and DAMLA TURGUT, "WCA: A Weighted Clustering Algorithm for Mobile Ad Hoc Networks", Cluster Computing 5, 193-204, 2002.

[18] Mohammad Shayesteh and Nima Karimi, “An Innovative Clustering Algorithm for MANETs Based on Cluster Stability", International Journal of Modeling and Optimization, Vol. 2, No. 3, June 2012 